\title{
TELD with limited foraminoplasty has potential biomechanical advantages over TELD with large annuloplasty: an in-silico study
}

Jingchi $\mathrm{Li}^{1 \dagger}$, Chen $\mathrm{Xu}^{2 \dagger}$, Xiaoyu Zhang ${ }^{3 \dagger}$, Zhipeng Xi ${ }^{3}$, Mengnan $\mathrm{Liu}^{4}$, Zhongxin Fang ${ }^{5}$, Nan Wang $^{3}$, Lin Xie ${ }^{3^{*}}$ and Yueming Song ${ }^{1 *}$

\begin{abstract}
Background: Facetectomy, an important procedure in the in-out and out-in techniques of transforaminal endoscopic lumbar discectomy (TELD), is related to the deterioration of the postoperative biomechanical environment and poor prognosis. Facetectomy may be avoided in TELD with large annuloplasty, but iatrogenic injury of the annulus and a high grade of nucleotomy have been reported as risk factors influencing poor prognosis. These risk factors may be alleviated in TELD with limited foraminoplasty, and the grade of facetectomy in this surgery can be reduced by using an endoscopic dynamic drill.
\end{abstract}

Methods: An intact lumbo-sacral finite element (FE) model and the corresponding model with adjacent segment degeneration were constructed and validated to evaluate the risk of biomechanical deterioration and related postoperative complications of TELD with large annuloplasty and TELD with limited foraminoplasty. Changes in various biomechanical indicators were then computed to evaluate the risk of postoperative complications in the surgical segment.

Results: Compared with the intact FE models, the model of TELD with limited foraminoplasty demonstrated slight biomechanical deterioration, whereas the model of TELD with large annuloplasty revealed obvious biomechanical deterioration. Degenerative changes in adjacent segments magnified, rather than altered, the overall trends of biomechanical change.

Conclusions: TELD with limited foraminoplasty presents potential biomechanical advantages over TELD with large annuloplasty. latrogenic injury of the annulus and a high grade of nucleotomy are risk factors for postoperative biomechanical deterioration and complications of the surgical segment.

\footnotetext{
*Correspondence: xielin6508@163.com; sym_cd@163.com

†Jingchi Li, Chen Xu and Xiaoyu Zhang contributed equally and should

be considered co-first authors of this study.

${ }^{1}$ Department of Orthopedic Surgery and Orthopedic Research Institute,

West China Hospital/West China School of Medicine for Sichuan

University, 37\# Wuhou Guoxue road, Chengdu, Sichuan Province 610041,

P.R. China

${ }^{3}$ Department of Spine Surgery, Affiliated Hospital of Integrated

Traditional Chinese and Western Medicine for Nanjing University

of Chinese Medicine, Nanjing, Jiangsu Province 210028, P.R. China

Full list of author information is available at the end of the article
}

(c) The Author(s) 2021. Open Access This article is licensed under a Creative Commons Attribution 4.0 International License, which permits use, sharing, adaptation, distribution and reproduction in any medium or format, as long as you give appropriate credit to the original author(s) and the source, provide a link to the Creative Commons licence, and indicate if changes were made. The images or other third party material in this article are included in the article's Creative Commons licence, unless indicated otherwise in a credit line to the material. If material is not included in the article's Creative Commons licence and your intended use is not permitted by statutory regulation or exceeds the permitted use, you will need to obtain permission directly from the copyright holder. To view a copy of this licence, visit http://creativecommons.org/licenses/by/4.0/. The Creative Commons Public Domain Dedication waiver (http://creativeco mmons.org/publicdomain/zero/1.0/) applies to the data made available in this article, unless otherwise stated in a credit line to the data. 
Keywords: Biomechanical deterioration, Transforaminal endoscopic lumbar discectomy, Endoscopic dynamic drill, Facetectomy, latrogenic annulus injury

\section{Background}

The discovery of the Kambin triangle [1] was rapidly followed by the enhanced use of transforaminal endoscopic lumbar discectomy (TELD) for the treatment of lumbar disc herniation (LDH) [2]. Facetectomy is an important procedure in the in-out and out-in techniques of TELD [3-5]. The procedure involves foramen enlargement via the removal of part of the superior articular process (SAP) and ligamentum structures [6-8]. Facetectomy is useful for expanding the surgical field and decompressing the exiting nerve root, especially in patients with foramen stenosis [4, 9-12].

The zygapophyseal joint (ZJ) guides spinal motion, transfers a substantial amount of the compressive load and bending and shearing moments (i.e. limits excessive motion) and protects structures in the functional spinal unit (FSU) [13-20]. Pathological changes in spinal load distribution may occur after high-grade facetectomy, resulting in injury to the surgical FSU, which is a risk factor for symptom recurrence and disc degeneration [16, 21-23]. The ZJ is an important structure for maintaining spinal stability $[13,14,24]$. Instability in the surgical segment caused by facetectomy is a risk factor for biomechanical deterioration, which results in degeneration of the surgical FSU and poor long-term prognosis [19-22, 25]. These deductions are consistent with the findings of our published finite element (FE) numerical studies [2628], which demonstrated that a higher grade facetectomy might be associated with biomechanical deterioration and lumbar instability; these changes may be related to further degeneration and symptom recurrence [27-29]. Because axial rotation could enhance the vulnerability of the posterior annulus and the ZJ could restrict lumbar spinal motion under axial rotation, iatrogenic injury of the SAP in TELD may also increase the risk of annulus tear, recurrence of related symptoms and acceleration of disc degeneration $[17,18,24,30]$.

The standard in-out technique could be modified to avoid facetectomy in TELD for patients without foramen stenosis. In this modification, hereafter referred to as large annuloplasty, the cannula is inserted into the disc space via the Kambin triangle. The herniated disc is then removed without damage to the SAP (i.e. without facetectomy) by pressing down on the cannula and using different sizes of bending forceps. This technique avoids the related risks of biomechanical deterioration and postoperative complications (Fig. 1).

Despite the benefits of modification, however, the optimised in-out surgical strategy retains its original defects, which may also lead to poor clinical outcomes. Specifically, the risk of recurrent lumbar disc herniation (RLDH) has been reported to increase dramatically with the

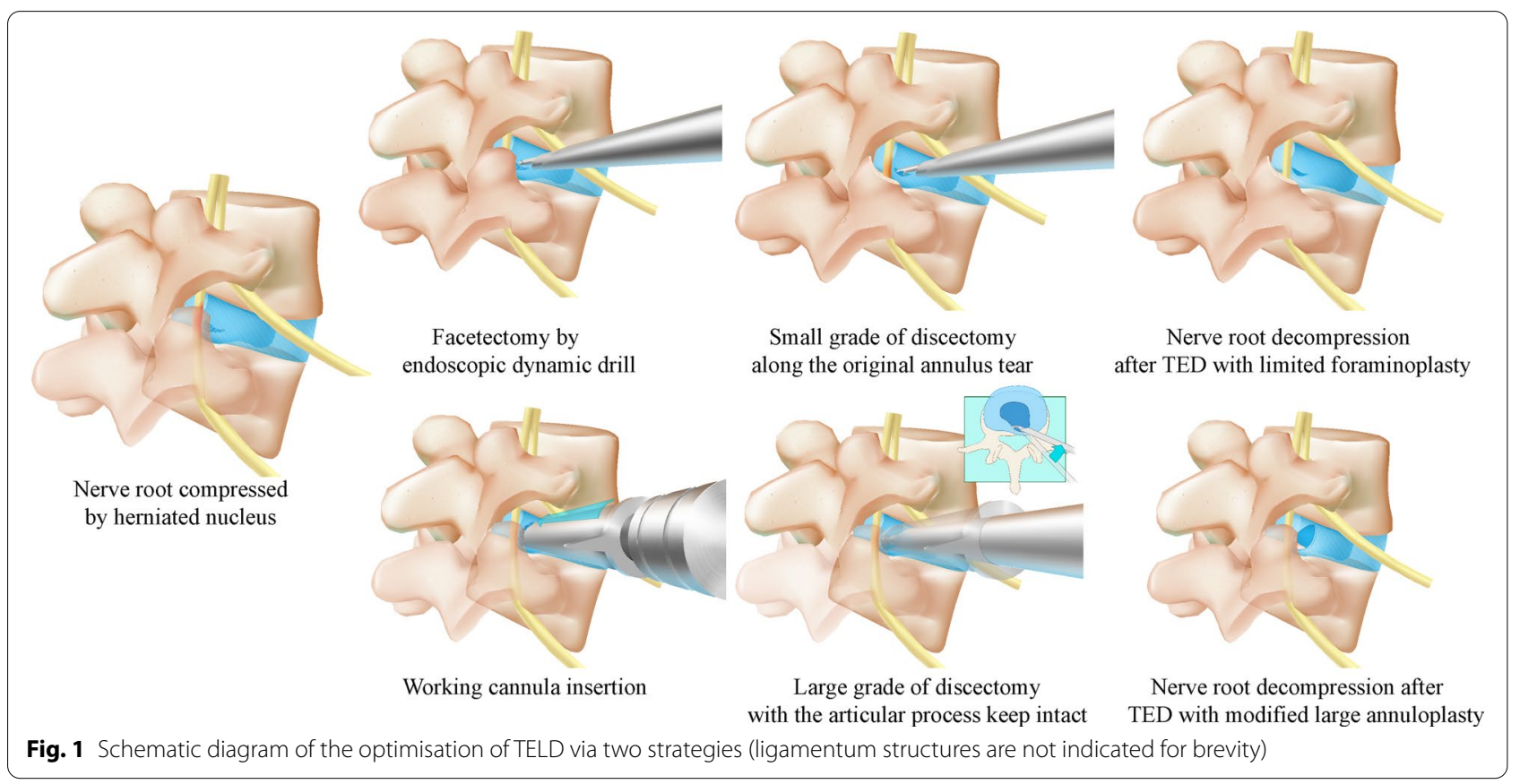


expansion of the annulus tear (i.e. by over $25 \%$ when the annulus tear is larger than $6 \mathrm{~mm}$ ) [31-35]. The strength of the scar tissue in the outer lamellae of the annulus is insufficient to prevent RLDH [36, 37]. Considering that the diameter of our working cannula is $7.5 \mathrm{~mm}$ (Type WTS127502, Joimax International, Irvine, CA, USA) and its insertion would inevitably lead to iatrogenic injury of the annulus, a higher grade of nucleotomy in the modified in-out TELD technique appears to be necessary to prevent RLDH (Fig. 1) [3]; unfortunately, this surgical strategy also presents limitations.

Preservation of the residual nucleus postoperatively is important to maintain spinal biomechanical function [19, $38,39]$. A high grade of nucleotomy may lead to the pathological distribution of stress in the annulus and render the latter vulnerable to fatigue damage under cyclic loading [38-41]. Such damage may result in annulus tears, which could accelerate disc degeneration. Disc collapse could also be accelerated by this pathological process $[16$, $39,40]$, and the risk of lumbar instability may increase on account of the laxity of soft tissues. The incidence of foramen stenosis could increase as a result of the decrease in foramen cross-sectional area (CSA) following the collapse of the surgical FSU without facetectomy $[24,25,42]$. Hence, a higher incidence of symptom recurrence may be observed in patients with higher grades of nucleotomy $[16,23]$. The collapse of the surgical segment and disc degeneration may also lead to irregular secondary spinal load transmission, which has been proven to increase the load of the ZJ cartilage and the risk of ZJ osteoarthritis (ZJOA), hypertrophy of the articular process and spinal stenosis [43-45]. Thus, a higher grade of nucleotomy, the remedial action prescribed to reduce the risk of RLDH caused by iatrogenic annulus tears in the in-out technique, may lead to greater risks of poor clinical outcomes and low satisfaction in patients after TELD [32].

A high grade of nucleotomy as a remedial procedure for iatrogenic annulus injury is not usually necessary in the out-in technique of TELD. If the size of the original annulus tear is less than $6 \mathrm{~mm}$, the residual annulus tissue is not generally expected to lead to serious clinical symptoms [46]. Nucleotomy could be accomplished along the original annulus tear without any iatrogenic annulus injury. Discectomy can be accomplished in patients with the contained type of LDH (i.e. LDH with an intact annulus) by using bipolar radiofrequency to produce a small slit (i.e. less than $6 \mathrm{~mm}$ ) in the annulus; in this case, higher grades of nucleotomy are unnecessary. Facetectomy may be limited by endoscopic dynamic drill for which could be accomplished precisely under direct version with its assistance. In our clinical practice, we successfully restricted the grade of facetectomy to less than one-third for patients without foramen stenosis and protected the ZJ cartilage and capsule (Fig. 1 and Fig. 2). More importantly, the controllable risk of postoperative spinal instability and biomechanical deterioration after endoscopic nucleotomy with a low grade of facetectomy was proven in our published studies [26-28].

Having established the above theoretical and practical foundation, we hypothesise that, even if an iatrogenic injury of the SAP could be avoided, compared with TELD with large annuloplasty, the modified out-in technique of TELD, hereafter referred to as limited foraminoplasty, presents potential biomechanical advantages. This hypothesis was verified by examining the biomechanical

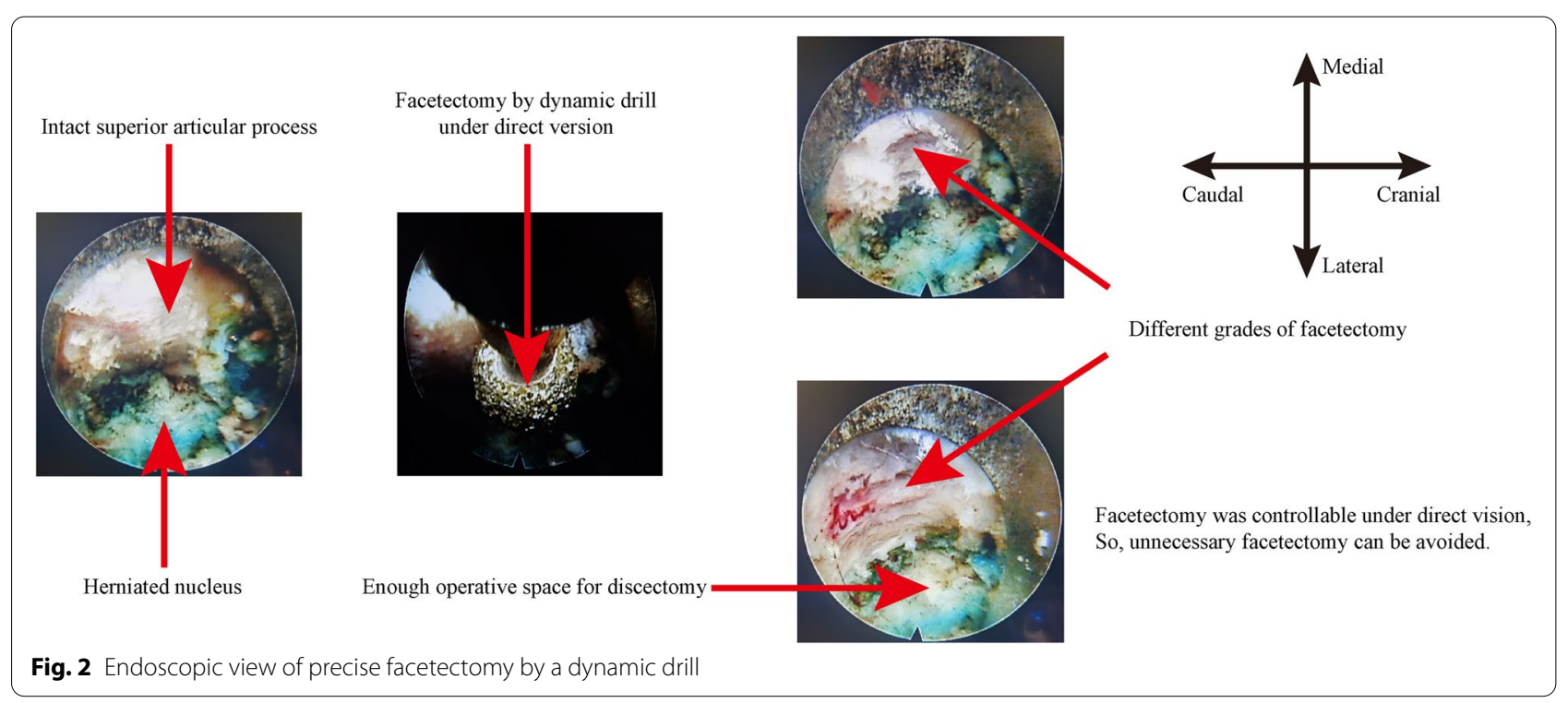


effects of TELD with large annuloplasty and TELD with limited foraminoplasty via validated three-dimensional lumbo-sacral models. LDH patients are often middleaged or elderly, and degenerative changes in their original discs may have potential impacts on the postoperative biomechanical environment [23, 47, 48]. Herein, surgical simulations and FE analysis were accomplished using models with and without degeneration. To the best of our knowledge, this research is the first to provide real evidence clarifying these issues.

\section{Methods}

\section{Model construction}

An intact FE model of L3-S1 was constructed in our published studies [26, 28, 49]. The bone structures in this model included cortical, cancellous and posterior structures and the nonbony components included intervertebral discs and ZJ cartilages. The IVD consisted of the nucleus core, the surrounding annulus and cartilage endplates [50,51], and the thickness of the cortical structures and endplates was set to $0.8 \mathrm{~mm}$ $[47,48,52]$. Ligaments and ZJ capsules were constructed by cable elements $[49,53]$. Facet cartilages were defined by surface-surface contact elements, and the gap between cartilages was set to $0.5 \mathrm{~mm}[47,54]$. In the model of disc degeneration in segments adjacent to the surgical segment, the disc height was reduced to $67 \%$, the CSA of the annulus was increased by $40 \%$ and the material properties of the annulus and nucleus were modified according to previously published studies (Fig. 3) [23, 47, 48].

\section{Boundary and loading conditions}

The intact models were set to be symmetric in the sagittal plane to increase their computational efficiency by allowing the unilateral calculation of the bending and axial rotation loading conditions [27]. Different sizes of hybrid elements were established in the FE models, and the mesh was refined as thin structures and structures with large deformation $[27,49,55]$. A mesh convergency test was performed on the intact models by evaluating the change in maximum annulus shear stress to ensure the computational credibility of a model; the model was considered to be converged if the change in computational value was less than $3 \%$. All degrees of freedom were fixed under the $\mathrm{S} 1$ inferior, stress and moments were applied to the L3 superior $[49,56]$ and the contact between facet cartilages was considered frictionless $[53,56]$.

\section{Model calibration and validation}

During model calibration, the stiffness of the ligamentum structures was slightly modified within the physiological range to reduce differences between the computed biomechanical indicators and those described in widely cited in-vitro studies [50, 56-61]. The reliability of the calibrated model was then ensured by conducting multi-indicator model validation, which was accomplished by comparing the computed range of motion (ROM), intradiscal pressure (IDP) and disc compression (DC) with the results of previous in-vitro studies under different loading conditions [62-65].
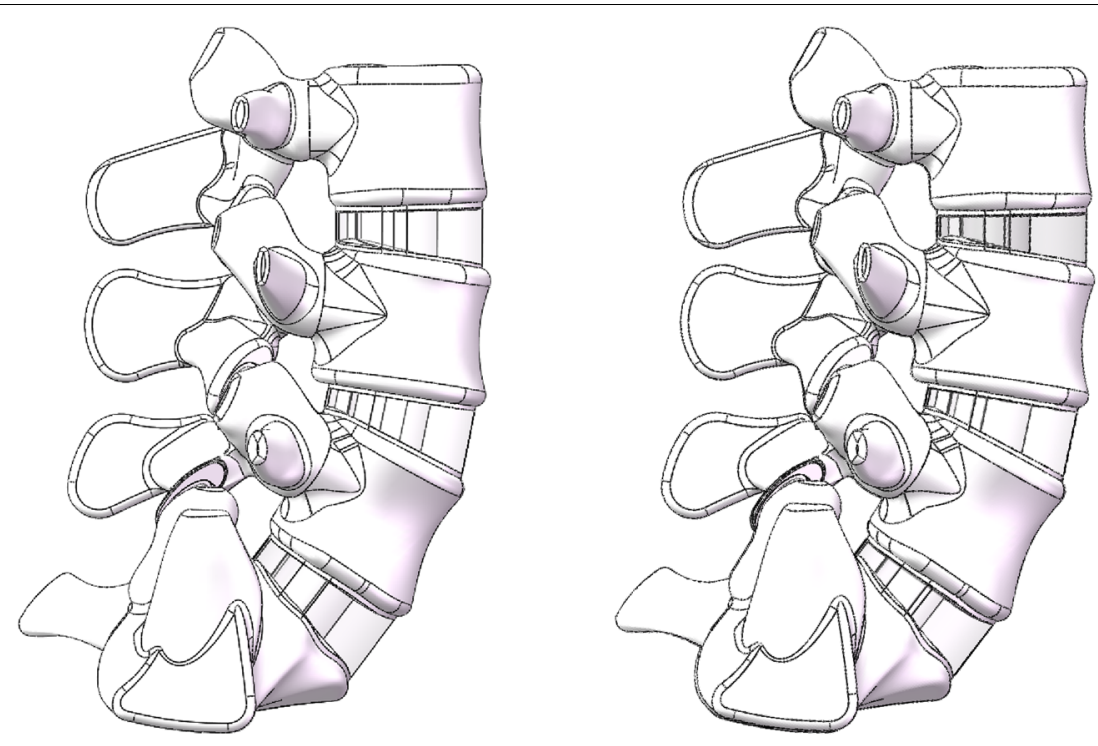

Model without disc degeneration

Model with disc degeneration in L3-L4 and L5-S1 segments

Fig. 3 Intact 3D models constructed in the current study 


\section{Simulation of TELD with large annuloplasty and which with limited foraminoplasty}

The right side of segment L4-L5 was selected to simulate TELD. TELD with limited foraminoplasty was simulated according to a reported surgical technique and our clinical experience $[4,49]$. In brief, a $3 \mathrm{~mm}$ long and $1 \mathrm{~mm}$ wide incision was made on the annulus to simulate the annulus tear. One-sixth of the nucleus around the incision was removed to simulate a low-grade nucleotomy. The vertex of the facetectomy was located on the cranial tip of the SAP, and one-third of the SAP and ligamentum flavum (LF) was excised (Fig. 4) [6, 7, 26, 49]. The simulation of TELD with large annuloplasty and intact SAP was conducted by setting the original annulus tear as the centre of working cannula insertion. The surrounding $7.5 \mathrm{~mm}$ area of the annulus was completely deleted to simulate iatrogenic injury. One-third (i.e. twice the range of nucleotomy in TELD with limited foraminoplasty) of the nucleus around the annulus tear was removed to simulate a high-grade nucleotomy (Fig. 4). Pathological changes caused by DD were simulated in segments L3L4 and L5-S1, and the surgical simulation was kept consistent between models with and without DD (Fig. 4). The FE models constructed in this study were named Models 1-6 to simplify the discussion (Table 1).

\section{Results}

\section{Model validation}

The computational accuracy (ACC) of the models is presented in Fig. 5. In this study, the ACC for all parameters determined, except for DC in segment L3-L4, exceeded $90 \%$. The ACC of DC in segment L3-L4 was $85.2 \%$, and the difference between our computational result and the average value determined from an in-vitro study was

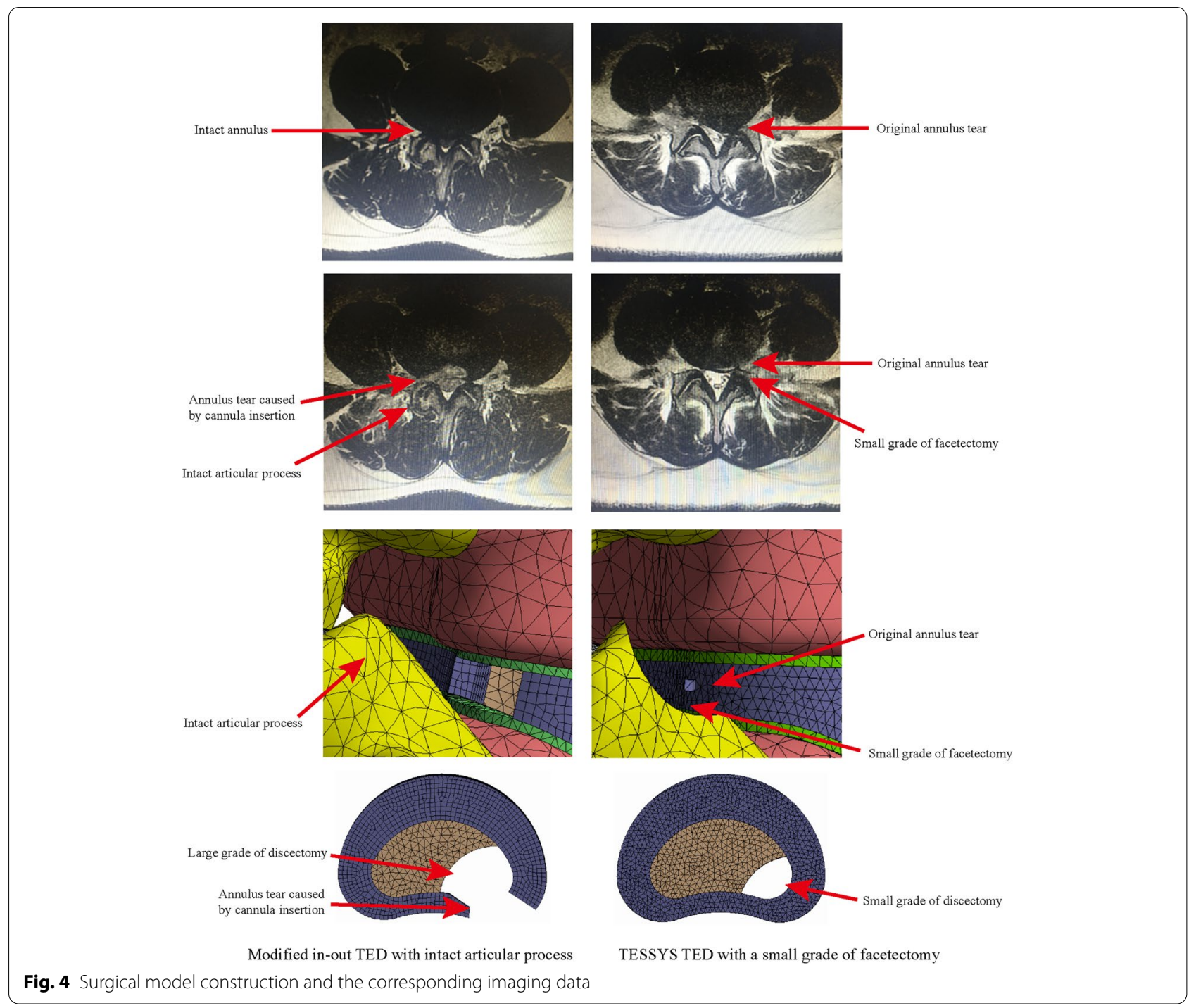


Table 1 Summary table of named FE models

\begin{tabular}{lll}
\hline & $\begin{array}{l}\text { Models without disc } \\
\text { degeneration }\end{array}$ & $\begin{array}{l}\text { Models with adjacent } \\
\text { segments disc } \\
\text { degeneration }\end{array}$ \\
\hline $\begin{array}{l}\text { Intact model } \\
\begin{array}{l}\text { TELD models } \\
\text { with large } \\
\text { annuloplasty }\end{array}\end{array}$ & 2 & 4 \\
$\begin{array}{l}\text { TELD models } \\
\text { with limited } \\
\text { foraminoplasty }\end{array}$ & 3 & 5 \\
\hline
\end{tabular}

clearly less than one standard deviation [58]. Moreover, DD in segments adjacent to the surgical segment led to slight increases in IDP and decreases in facet contact force (FCF) in the surgical segment, which is consistent with published studies $[23,48]$. Thus, we believe that our models represent the actual biomechanical environment well.

\section{Biomechanical change in different models}

The concept of FCF is emphasised here. FCF was not recorded during flexion because cartilages under this loading condition were not in contact. Besides, cartilages in the bending side were in contact, and the opposite side of cartilages were in contact in the axial rotation condition. In other words, FCF under left lateral bending is observed on left-side cartilages, whilst FCF under left axial rotation is observed on right-side cartilages and vice versa.
Biomechanical indicators related to the acceleration of DD, ZJOA, segmental instability and spinal stenosis in the surgical segment were computed and recorded (Figs. 6, 7, 8 and 9). Compared with the intact models, the models simulating TELD with limited foraminoplasty showed slight degenerative changes under most loading conditions, whilst the models simulating TELD with large annuloplasty revealed obvious biomechanical deterioration. Most of the biomechanical indicators in the surgical segment, except for FCF and ROM, deteriorated with DD in adjacent segments, and the change trends of the original biomechanical parameters in postoperative models did not vary or clearly increase in the degenerated models.

Obvious biomechanical changes were observed during bending and rotation to the surgical side (i.e. right lateral bending and axial rotation). Specifically, a difference of over $40 \%$ in maximum von Mises stress and strain energy was observed on the cartilage endplates during right bending and rotation, and the difference in cartilage strain energy under right rotation exceeded $100 \%$ in different postoperative models (Fig. 6). A difference in maximum shear and compressive stress of over $100 \%$ was noted under the condition of right rotation (Fig. 7). Whilst the overall trend was identical to those of the above indicators, changes in FCF and ROM in the different models were relatively minor (Fig. 8). Foraminoplasty could obviously enlarge the area of the foramen in the surgical site, and the area in TELD models with large

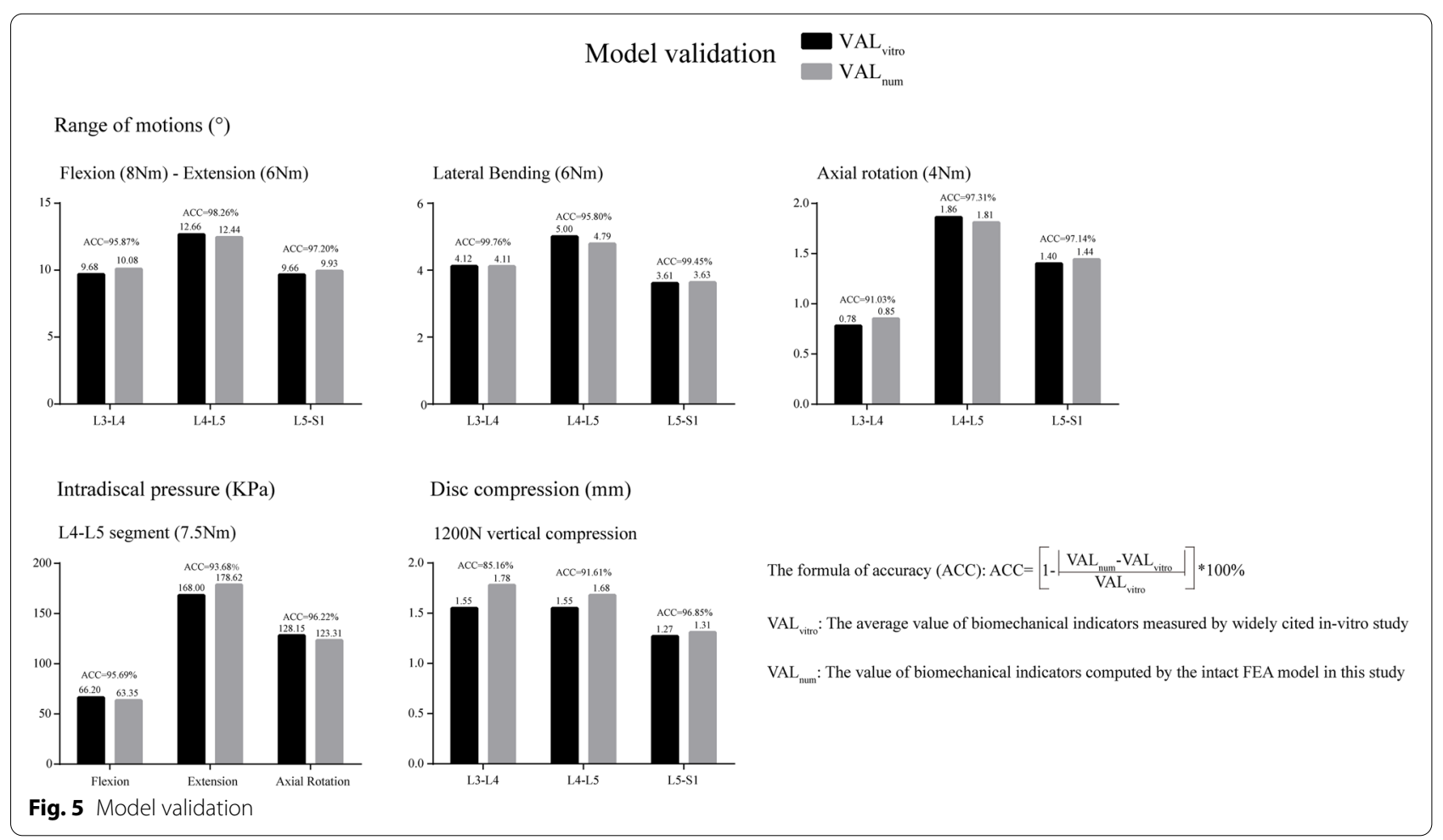



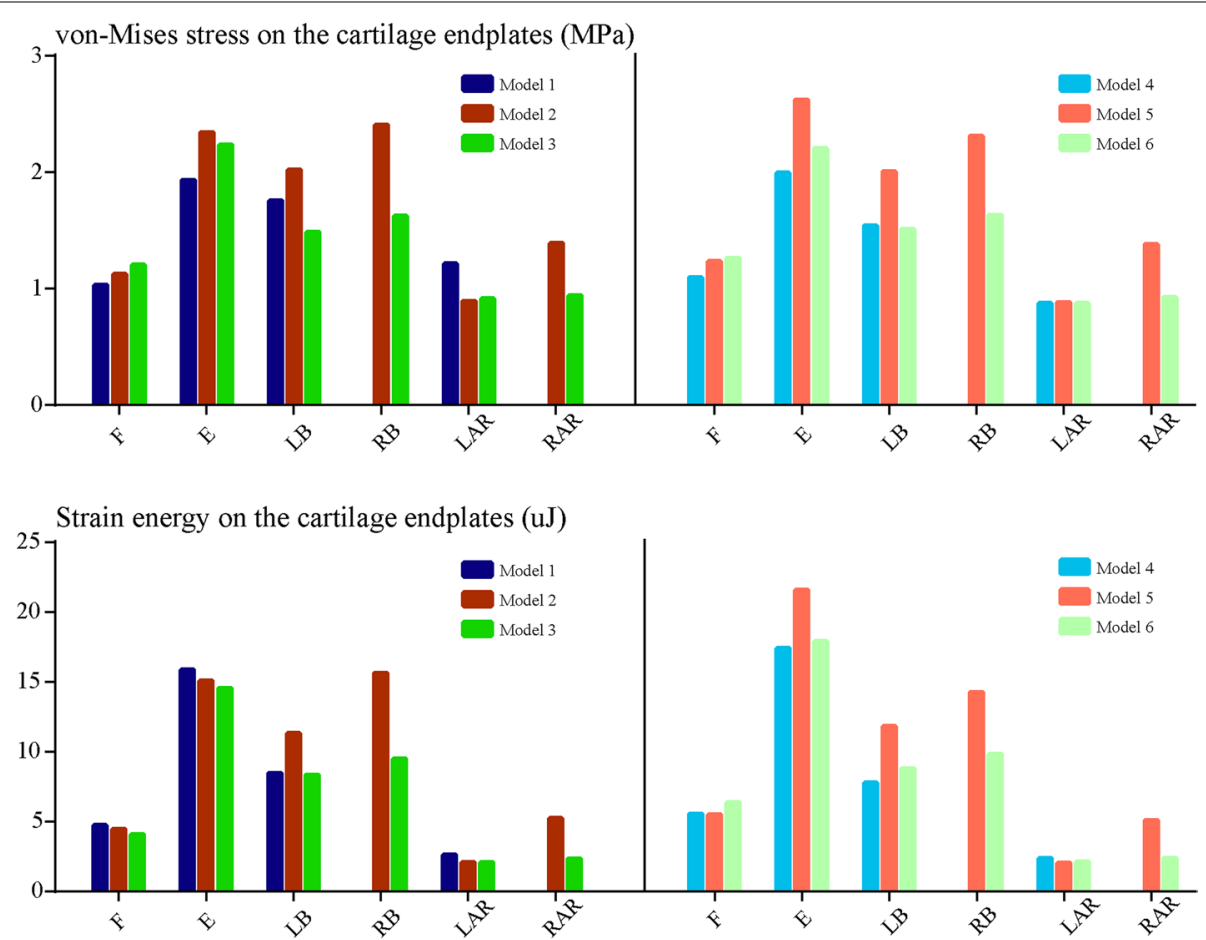

Fig. 6 Variations in biomechanical indicators related to 'endplate-type' disc degeneration. F: flexion, E: extension, LB: left bending, RB: right bending, LAR: left axial rotation, RAR: right axial rotation. The descriptions of Models 1-6 are provided in Table 1
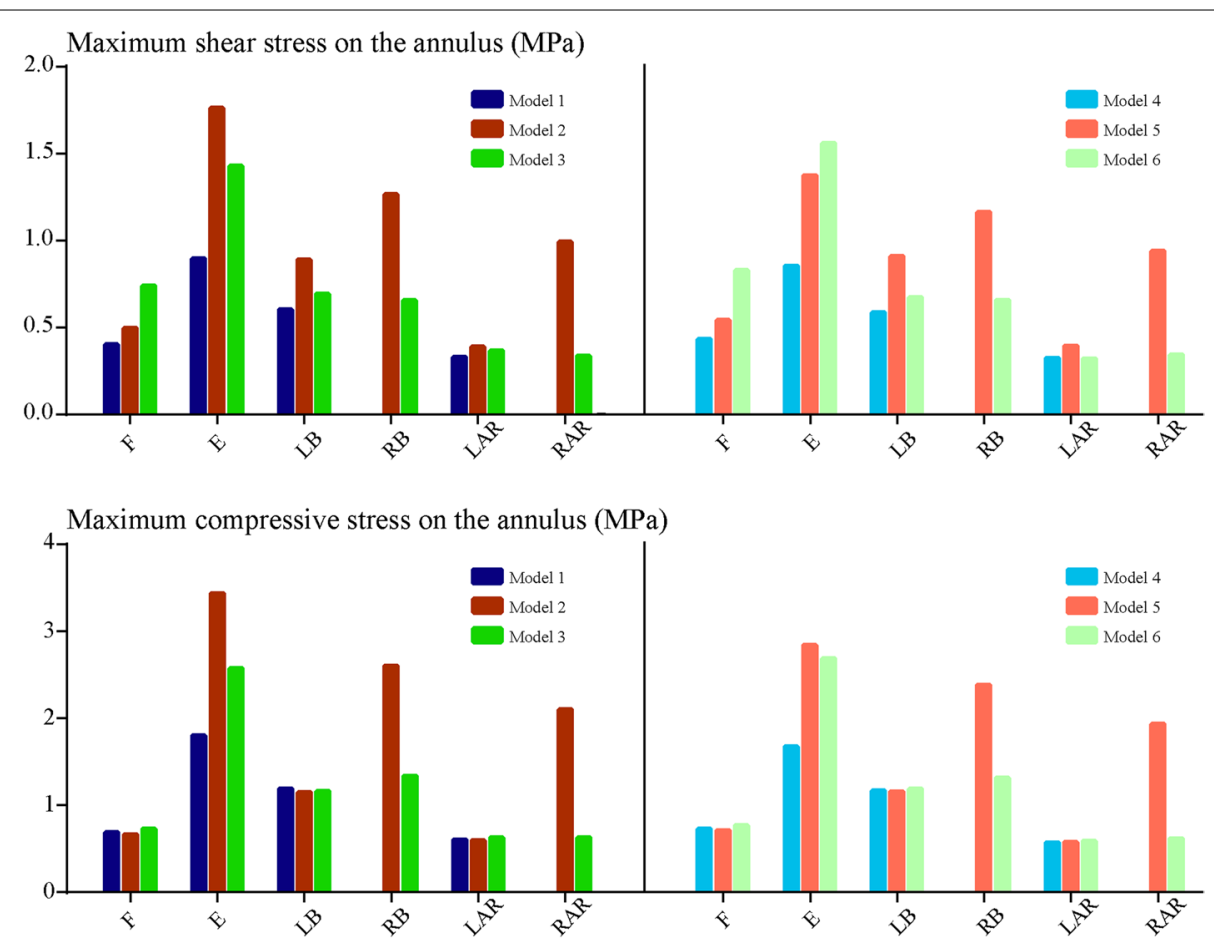

Fig. 7 Variations in biomechanical indicators related to 'annulus-type' disc degeneration 

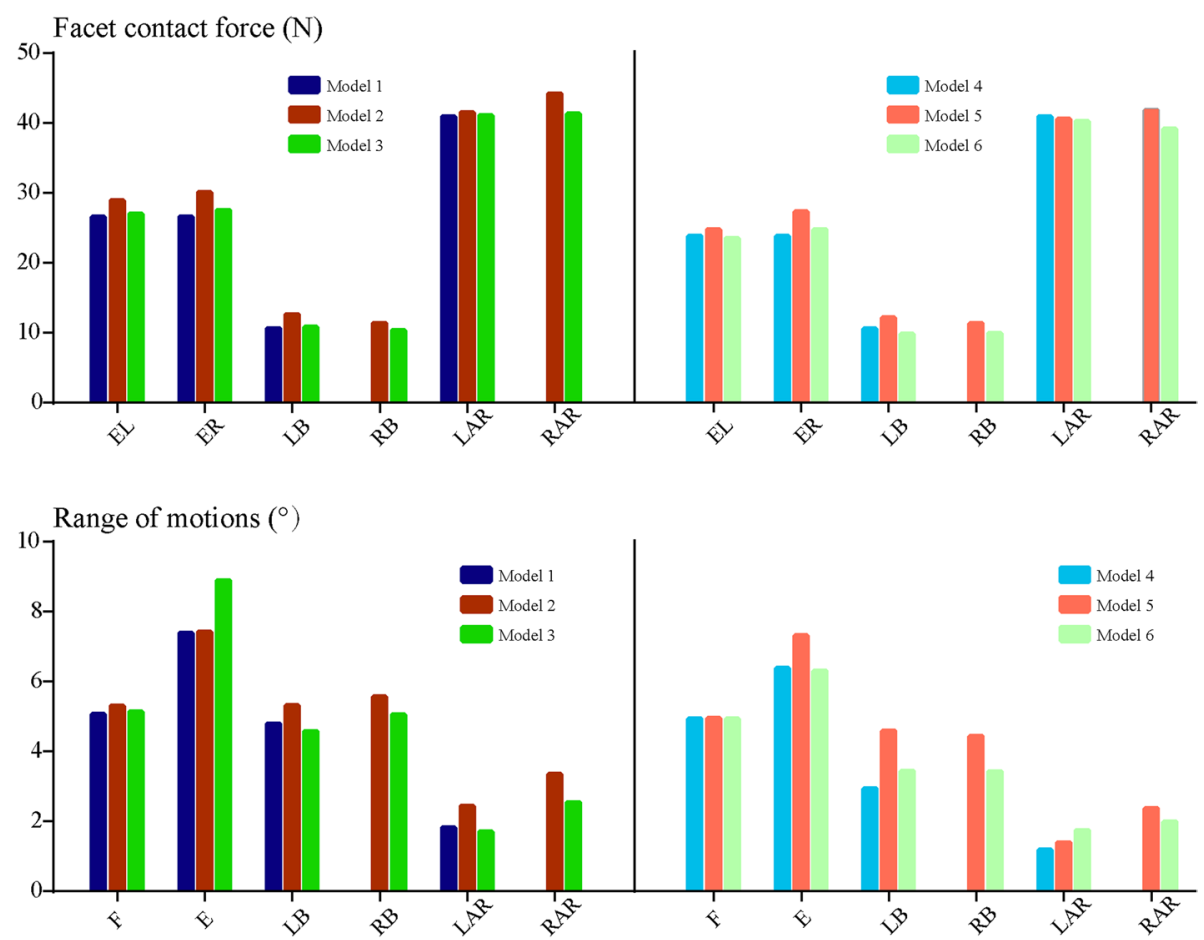

Fig. 8 Variations in biomechanical indicators related to ZJ degeneration and lumbar instability
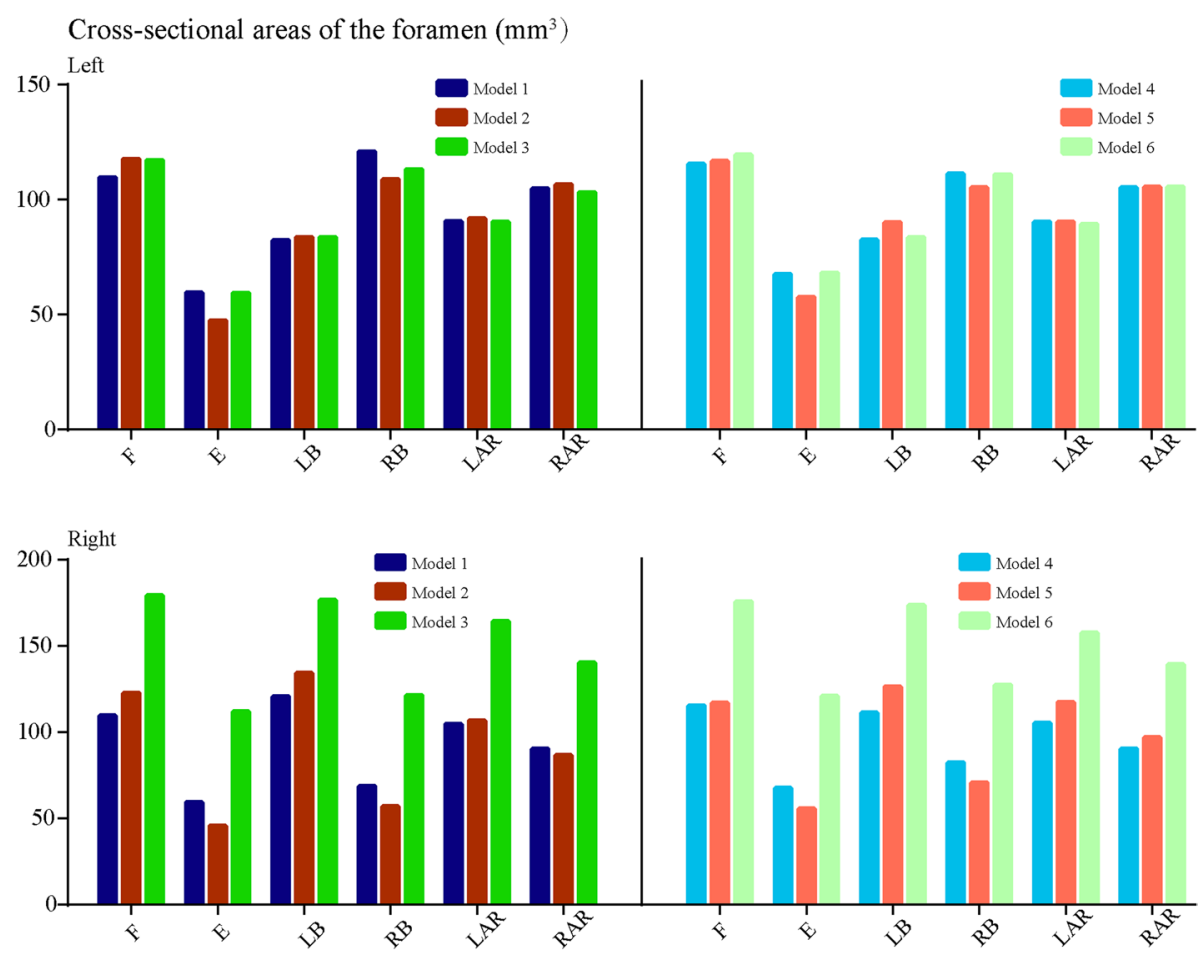

Fig. 9 Variations in CSA 
annuloplasty was even smaller than preoperative models under extension and right bending conditions (Fig. 9).

Obvious biomechanical changes can be observed in bending and rotation conditions to the surgical side (i.e. right lateral bending and axial rotation). Specifically, greater than $40 \%$ difference in maximum von-Mises stress and strain energy on the cartilage endplates can be observed in right bending and rotation conditions, and the difference in the cartilage strain energy under right rotation was even more than $100 \%$ in different postoperative models (Fig. 6). Besides, more than 100\% difference in the maximum shear and compressive stress was evaluated under right rotation condition (Fig. 7). In contrast, while the overall trend was the same as the above indicators, the changes of FCF and ROM in different models were relatively minor (Fig. 8). Additionally, foraminoplasty could obviously enlarge the area of foremen in the surgical side, and which in TELD models with large annuloplasty was even smaller than preoperative models under extension and right bending conditions (Fig. 9).

\section{Discussion}

\section{Objective of this study}

This work evaluated the risks of biomechanical deterioration and postoperative complications in the surgical segment caused by TELD with large annuloplasty and intact SAP and TELD with limited foraminoplasty and without annuloplasty. Intact lumbo-sacral models with and without disc degeneration and the corresponding models obtained after the investigated operations were performed were constructed, and biomechanical indicators closely related to lumbar degenerative diseases were computed and evaluated. The importance of the biomechanical environment for achieving positive postoperative clinical outcomes has been repeatedly demonstrated $[23,49,51]$. Thus, investigations on the biomechanical changes caused by two different surgical techniques of TELD are of great significance for optimal surgical strategy selection.

\section{Notable points in the model construction process}

Adjacent segments, rather than the surgical segment itself, were selected to construct the DD models. This model construction strategy is based on our clinical experience. As mentioned earlier, DD is very common in TELD patients. This nature of degenerative change may not always lead to serious clinical symptoms but could adversely affect the biomechanical environment in adjacent segments [23, 47, 48]. Hence, simulations of disc degeneration are meaningful for the evaluation of real postoperative biomechanical environments. Disc collapse during DD could lead to reductions in the CSA of the Kambin triangle, and the risk of exiting nerve root injury in a degenerated disc increases during the insertion of the working cannula without facetectomy [66, 67]. As such, LDH with a narrow disc space may be considered a contraindication for the application TELD with large annuloplasty, and the surgical segment was excluded during the construction of degenerative change models.

Although ZJ degeneration has been closely related to DD $[43,45,57,68]$ and some FE studies have constructed ZJ degenerative models by reducing the facet gap [47, 56], in this work, we abandoned the construction of ZJ degeneration. The gap thickness of the ZJ should reflect the cartilage wear, sclerosis and hyperplasia of subchondral bone [59, 69, 70], but these pathological processes are difficult to simulate during model construction. Specifically, decreasing the facet gap by increasing the thickness of the facet cartilage is completely contrary to the pathological changes accompanying ZJ degeneration. Besides, if the gap is reduced by increasing the thickness of the bone tissue of the articular process, the definitions of material properties for sclerotic subchondral bone structures, which obviously differ from those of normal bone tissues, become inaccurate $[15,71,72]$, and the casual definition of material properties without reliable data will reduce the credibility of this study. Hence, we chose to construct DD models without a change in facet gap $[48,56]$.

The grades of facetectomy in the out-in TELD models and discectomy in the in-out TELD models were set as one-third, consistent with the maximum value we have observed in our clinical practice. This modelling strategy was selected because facetectomy and nucleotomy were previously assumed to be the main reasons behind the poor clinical outcomes obtained after these operations. Therefore, higher grades of these two procedures could lead to more pronounced biomechanical deterioration and provide a clearer reference for evaluating these techniques.

\section{Clinical significance of biomechanical indicators}

Disc collapse and DD acceleration in the surgical segment and the resulting secondary pathological changes are the most significant causes of poor clinical outcomes in patients following non-fusion lumbar surgery $[33,73,74]$. As reported by Adam et al., the injury of the endplates and annulus may be considered two different pathways in the DD process [21]. The maximum von Mises stress and strain energy of the endplates were recorded to evaluate the risk of DD caused by endplate lesions and ossification. Endplates play a key role in pressure distribution. Postoperative abnormal stress concentration on the endplates increases the risk of lesions in these structures [21, $75,76]$ and may result in inflammatory responses, autoimmune reactions and disc innervation, all of which are considered significant triggers for DD acceleration and increased risk of lower back pain (LBP) [50, 77-79]. 
IVD is an avascular structure, and the most important pathway for its metabolism is trans-endplate diffusion [80, 81]. According to Wolff's law, the concentration of strain energy, a type of compensatory reaction to endplate stress concentration, may be considered a predictive factor for IVD ossification [82, 83]. Occlusion of the trans-endplate diffusion pathway could lead to DD acceleration [43, 79, $84,85]$. Endplate injury caused by abnormal stress concentration is closely associated with the disruption of the annulus and may be reflected by the deterioration of the biomechanical indicators of this structure, especially in its post and post-lateral parts [21, 29, 81]. The concentration of shear and compressive stresses has been proven to be related to different types of annulus tears and the resulting $\mathrm{DD}$, thereby resulting in discogenic LBP and RLDH $[22,23,84]$. Hence, we can speculate that the above biomechanical indicators are credible predictors for the assessment of postoperative prognosis.

Foramen stenosis is another vital reason behind the deterioration of clinical outcomes. Special attention should be paid to models after in-out TELD with intact SAP because the risk of foramen stenosis increases with disc collapse caused by a higher grade of discectomy in the surgical segment without foraminoplasty [73, 74, 86]. An increase in FCF is a risk factor for not only cartilage wear and the resulting degenerative osteoarthritis of the ZJ [15, 44, 72], a trigger of LBP [22, 25, 45], but also foramen stenosis because larger loads could promote osteogenic activity [43, 82, 87]. More importantly, disc collapse and degeneration of the surgical segment lead to pathological stress concentration on the ZJ cartilages, resulting in degenerative osteoarthritis and osteophyte formation [15, 45]. Lumbar instability, which has been proven to be related to LBP and further DD, is an important cause of deterioration after non-fusion surgery $[85,88,89]$. Therefore, ROM can be used as an indicator not only for model validation but also for the assessment of postoperative complications, and close interactions were observed amongst different biomechanical indicators.

Biomechanical deterioration can generally be observed in models with DD. Although DD in adjacent segments did not obviously exacerbate biomechanical deterioration in the surgical segment, the vicious cycle of DD could be observed; this finding highlights the significance of this FE study from a novel perspective [21, 90]. Specifically, in $\mathrm{DD}$, the deterioration of the biomechanical environment caused by inappropriate surgery may be continuously amplified and lead to a devastating prognosis. Therefore, the selection and optimisation of a surgical technique based on a biomechanical FE study are of great significance.
The risk of endplate calcification, annulus tears and the resulting DD in the surgical segment may be remarkably accelerated in patients after TELD with large annuloplasty, and the potential risk they present to surgical segment instability, ZJOA and the compression of existing nerve roots should be taken into consideration. The biomechanical advantages of TELD with limited foraminoplasty indicate that the risk of these complications is generally lower in patients treated with this surgical method.

These speculations are consistent with previously published biomechanical reports. Specifically, nucleus removal could lead to the concentration of von Mises and compressive stresses on the annulus, particularly on the posterior and post-lateral rings of the structure, resulting in an increased risk of developing annulus microfractures and disc collapse [38, 91, 92]. In-vitro studies have noted an increase in FCF at denucleated segments [93]. These biomechanical and morphological changes have been reported to be initial triggers for symptom recurrence and poor prognosis in patients $[32,94]$.

\section{Limitations}

Firstly, ligaments were constructed by cable elements, and simulation of LF excision was accomplished by reducing the foramen CSA. Cable elements cannot stimulate the folding, hypertrophy and calcification of ligaments, and these pathological changes have been reported to be vital risk factors for spinal stenosis and nerve compression.

The proliferation of scar tissue on the annulus and its biomechanical effects cannot be evaluated; this issue is fairly common in FE studies. Considering that the size of annulus breakage is an important variable in this study, biomechanical changes brought about by the formation of annulus scar tissue, the strength of which cannot stop RLDH, may also exert potential biomechanical effects on patient prognosis. Hence, the current computational results should be interpreted with an awareness of this defect. Follow-up clinical studies are recommended to obtain more definitive conclusions.

\section{Conclusions}

Biomechanical deterioration can be observed in in-out TELD models with large annuloplasty and without facetectomy. Annuloplasty caused by the insertion of the working cannula and a high grade of nucleotomy to prevent RLDH may result in poor clinical outcomes for this surgical method. Modified out-in TELD with limited foraminoplasty appears to provide considerable biomechanical advantages. 


\begin{abstract}
Abbreviations
ACC: Accuracy; CSA: Cross-sectional areas; DC: Disc compression; FCF: Facet contact force; FE: Finite element; IVD: Intervertebral discs; IDP: Intradiscal pressures; LDD: Lumbar degenerative diseases; LDH: Lumbar disc herniation; LBP: Low back pain; LF: Ligamentum flavum; RLDH: Recurrent lumbar disc herniation; ROM: Range of motions; TELD: Transforaminal endoscopic lumbar discectomy; SAP: Superior articular process; YESS: Yeung endoscopic spine system; ZJ: Zygapophyseal joint.
\end{abstract}

\section{Acknowledgements}

We acknowledge Mr. Kepan Wang for the guidance of figures drawing.

\section{Authors' contributions}

LX and YMS contributed to the concept and design of the study, XYZ, ZXF and MNL contributed to the model construction, JCL and CX contribute to the finite element analysis, ZPX and NW drawn figures, JCL XC and XYZ wrote the manuscript, $L X$ and YMS checked the manuscript, all authors read and approved the final manuscript.

\section{Funding}

This study was funded by Foundation for leading talent in traditional Chinese medicine of Jiangsu province (2018SLJ0210) Key project of jiangsu province social development (BE2019765), and the innovative education project of Jiangsu Province Postgraduated student (SJCX20_0616). The funds provided by the above projects are used for the CT scan, the compensation of volunteer, the polishing of English manuscripts in the mother tongue, the conference affairs and travel expenses of studying courses related to threedimensional spinal modeling and finite element analysis and the publication charges of this manuscript.

\section{Availability of data and materials}

All the data of the manuscript are presented in the paper.

\section{Declarations}

\section{Ethics approval and consent to participate}

Approval for the current study protocol (including the lumbar CT scan) was obtained from the ethics committees of Affiliated Hospital of Integrated Traditional Chinese and Western Medicine for Nanjing University of Chinese Medicine (2019LWKY015).We confirm that the subject signed the informed consent and submitted it to the ethics committee for review before the examination, andall methods were carried out in accordance with relevant guidelines and regulations.

\section{Consent for publication}

Not Applicable.

\section{Competing interests}

The authors declare that they have no competing interests.

\begin{abstract}
Author details
${ }^{1}$ Department of Orthopedic Surgery and Orthopedic Research Institute, West China Hospital/West China School of Medicine for Sichuan University, 37\# Wuhou Guoxue road, Chengdu, Sichuan Province 610041, P.R. China. ${ }^{2}$ Department of Spine Surgery, Changzheng Hospital Affiliated to the Naval Medical University, Shanghai 200041, China. ${ }^{3}$ Department of Spine Surgery, Affiliated Hospital of Integrated Traditional Chinese and Western Medicine for Nanjing University of Chinese Medicine, Nanjing, Jiangsu Province 210028, P.R. China. ${ }^{4}$ Macau University of Science and Technology, Macau 999078, China. ${ }^{5}$ Fluid and Power Machinery Key Laboratory of Ministry of Education, Xihua University, Chengdu 610039, China.
\end{abstract}

Received: 16 April 2021 Accepted: 17 June 2021

Published online: 10 July 2021

\section{References}

1. Kambin P. Arthroscopic microdiscectomy. Spine J. 2003;3(3 Suppl):60s-4s.
2. Pan M, Li Q, Li S, Mao H, Meng B, Zhou F, Yang H. Percutaneous Endoscopic Lumbar Discectomy: Indications and Complications. Pain Physician. 2020;23(1):49-56.

3. Hoogland T, Schubert M, Miklitz B, Ramirez A: Transforaminal posterolateral endoscopic discectomy with or without the combination of a lowdose chymopapain: a prospective randomized study in 280 consecutive cases. Spine (Phila Pa 1976) 2006, 31(24):E890-897.

4. Wu B, Zhan G, Tian X, Fan L, Jiang C, Deepti B, Cao H, Li J, Lian Q, Huang $X$, et al. Comparison of Transforaminal Percutaneous Endoscopic Lumbar Discectomy with and without Foraminoplasty for Lumbar Disc Herniation: A 2-Year Follow-Up. Pain Res Manag. 2019;2019:6924941.

5. Yeung AT, Tsou PM: Posterolateral endoscopic excision for lumbar disc herniation: Surgical technique, outcome, and complications in 307 consecutive cases. Spine (Phila Pa 1976) 2002, 27(7):722-731.

6. Ruetten S, Komp M. Endoscopic Lumbar Decompression. Neurosurg Clin N Am. 2020;31(1):25-32.

7. Sivakanthan S, Hasan S, Hofstetter C. Full-Endoscopic Lumbar Discectomy. Neurosurg Clin N Am. 2020;31(1):1-7.

8. Xiong C, LiT, Kang H, Hu H, Han J, Xu F. Early outcomes of 270-degree spinal canal decompression by using TESSYS-ISEE technique in patients with lumbar spinal stenosis combined with disk herniation. Eur Spine J. 2019;28(1):78-86.

9. Choi G, Lee SH, Lokhande P, Kong BJ, Shim CS, Jung B, Kim JS: Percutaneous endoscopic approach for highly migrated intracanal disc herniations by foraminoplastic technique using rigid working channel endoscope. Spine (Phila Pa 1976) 2008, 33(15):E508-515.

10. Henmi T, Terai T, Hibino N, Yoshioka S, Kondo K, Goda Y, Tezuka F, Sairyo K. Percutaneous endoscopic lumbar discectomy utilizing ventral epiduroscopic observation technique and foraminoplasty for transligamentous extruded nucleus pulposus: technical note. J Neurosurg Spine. 2016:24(2):275-80.

11. Choi KC, Shim HK, Park CJ, Lee DC, Park CK. Usefulness of Percutaneous Endoscopic Lumbar Foraminoplasty for Lumbar Disc Herniation. World Neurosurg. 2017;106:484-92.

12. Yang J, Guo C, Kong Q, Zhang B, Wang Y, Zhang L, Wu H, Peng Z, Yan $Y$, Zhang D. Learning curve and clinical outcomes of percutaneous endoscopic transforaminal decompression for lumbar spinal stenosis. Int Orthop. 2020:44(2):309-17.

13. Szkoda-Poliszuk K, Żak M, Pezowicz C: Finite element analysis of the influence of three-joint spinal complex on the change of the intervertebral disc bulge and height. Int J Numer Method Biomed Eng 2018, 34(9):e3107.

14. Adams MA. Biomechanics of back pain. Acupunct Med. 2004:22(4):178-88.

15. Brown KR, Pollintine P, Adams MA. Biomechanical implications of degenerative joint disease in the apophyseal joints of human thoracic and lumbar vertebrae. Am J Phys Anthropol. 2008;136(3):318-26.

16. Naserkhaki S, Jaremko JL, Adeeb S, El-Rich M. On the load-sharing along the ligamentous lumbosacral spine in flexed and extended postures: Finite element study. J Biomech. 2016;49(6):974-82.

17. Newell N, Little JP, Christou A, Adams MA, Adam CJ, Masouros SD. Biomechanics of the human intervertebral disc: A review of testing techniques and results. J Mech Behav Biomed Mater. 2017:69:420-34.

18. Chen C, Jia Z, Han Z, Gu T, Li W, Li H, Tang Y, Wu J, Wang D, He Q, et al. Quantitative $T 2$ relaxation time and magnetic transfer ratio predict endplate biochemical content of intervertebral disc degeneration in a canine model. BMC Musculoskelet Disord. 2015;16:157.

19. Heuer F, Schmidt H, Claes L, Wilke HJ. Stepwise reduction of functional spinal structures increase vertebral translation and intradiscal pressure. J Biomech. 2007:40(4):795-803.

20. Heuer F, Schmidt H, Klezl Z, Claes L, Wilke HJ. Stepwise reduction of functional spinal structures increase range of motion and change lordosis angle. J Biomech. 2007:40(2):271-80.

21. Adams MA, Dolan P. Intervertebral disc degeneration: evidence for two distinct phenotypes. J Anat. 2012;221(6):497-506.

22. Clancy C, Quinn A, Wilson F. The aetiologies of Failed Back Surgery Syndrome: A systematic review. J Back Musculoskelet Rehabil. 2017:30(3):395-402.

23. Qasim M, Natarajan RN, An HS, Andersson GB. Damage accumulation location under cyclic loading in the lumbar disc shifts from inner annulus 
lamellae to peripheral annulus with increasing disc degeneration. J Biomech. 2014;47(1):24-31.

24. Mochida J, Nishimura K, Nomura T, Toh E, Chiba M: The importance of preserving disc structure in surgical approaches to lumbar disc herniation. Spine (Phila Pa 1976) 1996, 21(13):1556-1563; discussion 1563-1554.

25. Schaller B. Failed back surgery syndrome: the role of symptomatic segmental single-level instability after lumbar microdiscectomy. Eur Spine J. 2004;13(3):193-8

26. Li J, Zhang X, Xu W, Xi Z, Xie L. Reducing the extent of facetectomy may decrease morbidity in failed back surgery syndrome. BMC Musculoskelet Disord. 2019;20(1):369.

27. Li J, Xu W, Jiang Q, Xi Z, Zhang X, Wang N, Xie L, Liu Y. Indications Selection for Surgeons Training in the Translaminar Percutaneous Endoscopic Discectomy Based on Finite Element Analysis. Biomed Res Int. 2020;2020:2960642.

28. Li J, Li H, He Y, Zhang X, Xi Z, Wang G, Wang N, Xie L. The protection of superior articular process in percutaneous transforaminal endoscopic discectomy should decreases the risk of adjacent segment diseases biomechanically. J Clin Neurosci. 2020;79:54-9.

29. Adams MA, Roughley PJ: What is intervertebral disc degeneration, and what causes it? Spine (Phila Pa 1976) 2006, 31(18):2151-2161.

30. Hasegawa K, Kitahara K, Shimoda H, Hara T. Facet joint opening in lumbar degenerative diseases indicating segmental instability. J Neurosurg Spine. 2010;12(6):687-93.

31. McGirt MJ, Eustacchio S, Varga P, Vilendecic M, Trummer M, Gorensek M, Ledic D, Carragee EJ: A prospective cohort study of close interval computed tomography and magnetic resonance imaging after primary lumbar discectomy: factors associated with recurrent disc herniation and disc height loss. Spine (Phila Pa 1976) 2009, 34(19):2044-2051.

32. Carragee EJ, Spinnickie AO, Alamin TF, Paragioudakis S: A prospective controlled study of limited versus subtotal posterior discectomy: short-term outcomes in patients with herniated lumbar intervertebra discs and large posterior anular defect. Spine (Phila Pa 1976) 2006 31(6):653-657.

33. Carragee EJ, Han MY, Suen PW, Kim D. Clinical outcomes after lumbar discectomy for sciatica: the effects of fragment type and anular competence. J Bone Joint Surg Am. 2003;85(1):102-8.

34. Stokes IA, latridis JC: Mechanical conditions that accelerate intervertebral disc degeneration: overload versus immobilization. Spine (Phila Pa 1976) 2004, 29(23):2724-2732.

35. Faulhauer K, Manicke C. Fragment excision versus conventional disc removal in the microsurgical treatment of herniated lumbar disc. Acta Neurochir (Wien). 1995;133(3-4):107-11.

36. Kim HS, You JD, Ju Cl. Predictive Scoring and Risk Factors of Early Recurrence after Percutaneous Endoscopic Lumbar Discectomy. Biomed Res Int. 2019;2019:6492675.

37. Hampton D, Laros G, McCarron R, Franks D: Healing potential of the anulus fibrosus. Spine (Phila Pa 1976) 1989, 14(4):398-401.

38. O'Connell GD, Malhotra NR, Vresilovic EJ, Elliott DM: The effect of nucleotomy and the dependence of degeneration of human intervertebral disc strain in axial compression. Spine (Phila Pa 1976) 2011, 36(21):1765-1771.

39. Johannessen W, Cloyd JM, O'Connell GD, Vresilovic EJ, Elliott DM. Transendplate nucleotomy increases deformation and creep response in axial loading. Ann Biomed Eng. 2006;34(4):687-96.

40. Vresilovic EJ, Johannessen W, Elliott DM. Disc mechanics with trans-endplate partial nucleotomy are not fully restored following cyclic compressive loading and unloaded recovery. J Biomech Eng. 2006;128(6):823-9.

41. Cannella M, Arthur A, Allen S, Keane M, Joshi A, Vresilovic E, Marcolongo $M$. The role of the nucleus pulposus in neutral zone human lumbar intervertebral disc mechanics. J Biomech. 2008;41 (10):2104-11.

42. Kirkaldy-Willis WH, Wedge JH, Yong-Hing K, Reilly J: Pathology and pathogenesis of lumbar spondylosis and stenosis. Spine (Phila Pa 1976) 1978, 3(4):319-328.

43. Ganbat D, Kim YH, Kim K, Jin YJ, Park WM. Effect of mechanical loading on heterotopic ossification in cervical total disc replacement: a threedimensional finite element analysis. Biomech Model Mechanobiol. 2016;15(5):1191-9.

44. Kim HJ, Chun HJ, Lee HM, Kang KT, Lee CK, Chang BS, Yeom JS. The biomechanical influence of the facet joint orientation and the facet tropism in the lumbar spine. Spine J. 2013;13(10):1301-8.
45. Suri P, Miyakoshi A, Hunter DJ, Jarvik JG, Rainville J, Guermazi A, Li L, Katz $J N$. Does lumbar spinal degeneration begin with the anterior structures? A study of the observed epidemiology in a community-based population. BMC Musculoskelet Disord. 2011;12:202.

46. Mahatthanatrakul A, Kotheeranurak V, Lin GX, Hur JW, Chung HJ, Kim JS. Comparative analysis of the intervertebral disc signal and annulus changes between immediate and 1-year postoperative MRI after transforaminal endoscopic lumbar discectomy and annuloplasty. Neuroradiology. 2019;61(4):411-9.

47. Chuang WH, Lin SC, Chen SH, Wang CW, Tsai WC, Chen YJ, Hwang JR: Biomechanical effects of disc degeneration and hybrid fixation on the transition and adjacent lumbar segments: trade-off between junctional problem, motion preservation, and load protection. Spine (Phila Pa 1976) 2012, 37(24):E1488-1497.

48. Ruberté LM, Natarajan RN, Andersson GB. Influence of single-level lumbar degenerative disc disease on the behavior of the adjacent segments-a finite element model study. J Biomech. 2009;42(3):341-8.

49. Li J, Xu W, Zhang X, Xi Z, Xie L. Biomechanical role of osteoporosis affects the incidence of adjacent segment disease after percutaneous transforaminal endoscopic discectomy. J Orthop Surg Res. 2019;14(1):131.

50. Dreischarf M, Zander T, Shirazi-Adl A, Puttlitz CM, Adam CJ, Chen CS, Goel VK, Kiapour A, Kim YH, Labus KM, et al. Comparison of eight published static finite element models of the intact lumbar spine: predictive power of models improves when combined together. J Biomech. 2014:47(8):1757-66.

51. Herren C, Beckmann A, Meyer S, Pishnamaz M, Mundt M, Sobottke R, Prescher A, Stoffel M, Markert B, Kobbe P, et al. Biomechanical testing of a PEEK-based dynamic instrumentation device in a lumbar spine model. Clin Biomech (Bristol, Avon). 2017:44:67-74.

52. Tsouknidas A, Sarigiannidis SO, Anagnostidis K, Michailidis N, Ahuja S. Assessment of stress patterns on a spinal motion segment in healthy versus osteoporotic bony models with or without disc degeneration: a finite element analysis. Spine J. 2015;15(3 Suppl):S17-s22.

53. Du CF, Yang N, Guo JC, Huang YP, Zhang C. Biomechanical response of lumbar facet joints under follower preload: a finite element study. BMC Musculoskelet Disord. 2016;17:126.

54. Schmidt H, Galbusera F, Rohlmann A, Zander T, Wilke HJ: Effect of multilevel lumbar disc arthroplasty on spine kinematics and facet joint loads in flexion and extension: a finite element analysis. Eur Spine J 2012, 21(Suppl 5):S663-674.

55. Wang B, Hua W, Ke W, Lu S, Li X, Zeng X, Yang C. Biomechanical Evaluation of Transforaminal Lumbar Interbody Fusion and Oblique Lumbar Interbody Fusion on the Adjacent Segment: A Finite Element Analysis. World Neurosurg. 2019:126:e819-24.

56. Chuang WH, Kuo YJ, Lin SC, Wang CW, Chen SH, Chen YJ, Hwang JR: Comparison among load-, ROM-, and displacement-controlled methods used in the lumbosacral nonlinear finite-element analysis. Spine (Phila Pa 1976) 2013, 38(5):E276-285

57. Kim HJ, Kang KT, Son J, Lee CK, Chang BS, Yeom JS. The influence of facet joint orientation and tropism on the stress at the adjacent segment after lumbar fusion surgery: a biomechanical analysis. Spine J. 2015;15(8):1841-7.

58. Renner SM, Natarajan RN, Patwardhan AG, Havey RM, Voronov LI, Guo $\mathrm{BY}$, Andersson GB, An HS. Novel model to analyze the effect of a large compressive follower pre-load on range of motions in a lumbar spine. J Biomech. 2007;40(6):1326-32.

59. Woldtvedt DJ, Womack W, Gadomski BC, Schuldt D, Puttlitz CM: Finite element lumbar spine facet contact parameter predictions are affected by the cartilage thickness distribution and initial joint gap size. J Biomech Eng 2011, 133(6):061009.

60. Hsieh YY, Chen CH, Tsuang FY, Wu LC, Lin SC, Chiang CJ. Removal of fixation construct could mitigate adjacent segment stress after lumbosacral fusion: A finite element analysis. Clin Biomech (Bristol, Avon). 2017:43:115-20.

61. Ottardi C, Galbusera F, Luca A, Prosdocimo L, Sasso M, Brayda-Bruno M, Villa T. Finite element analysis of the lumbar destabilization following pedicle subtraction osteotomy. Med Eng Phys. 2016;38(5):506-9.

62. Schmidt H, Heuer F, Drumm J, Klezl Z, Claes L, Wilke HJ. Application of a calibration method provides more realistic results for a finite element model of a lumbar spinal segment. Clin Biomech (Bristol, Avon). 2007:22(4):377-84. 
63. Schmidt H, Heuer F, Simon U, Kettler A, Rohlmann A, Claes L, Wilke HJ. Application of a new calibration method for a three-dimensional finite element model of a human lumbar annulus fibrosus. Clin Biomech (Bristol, Avon). 2006;21 (4):337-44.

64. Wilson DC, Niosi CA, Zhu QA, Oxland TR, Wilson DR. Accuracy and repeatability of a new method for measuring facet loads in the lumbar spine. J Biomech. 2006;39(2):348-53.

65. Schilling C, Krüger S, Grupp TM, Duda GN, Blömer W, Rohlmann A. The effect of design parameters of dynamic pedicle screw systems on kinematics and load bearing: an in vitro study. Eur Spine J. 2011;20(2):297-307.

66. Pfirmann CW, Metzdorf A, Zanetti M, Hodler J, Boos N: Magnetic resonance classification of lumbar intervertebral disc degeneration. Spine (Phila Pa 1976) 2001, 26(17):1873-1878.

67. Xin G, Shi-Sheng H, Hai-Long Z. Morphometric analysis of the YESS and TESSYS techniques of percutaneous transforaminal endoscopic lumbar discectomy. Clin Anat. 2013;26(6):728-34.

68. Park WM, Kim K, Kim YH. Effects of degenerated intervertebral discs on intersegmental rotations, intradiscal pressures, and facet joint forces of the whole lumbar spine. Comput Biol Med. 2013;43(9):1234-40.

69. Ichchou L, Allali F, Rostom S, Bennani L, Hmamouchi I, Abourazzak FZ, Khazzani H, El Mansouri L, Abouqal R, Hajjaj-Hassouni N. Relationship between spine osteoarthritis, bone mineral density and bone turn over markers in post menopausal women. BMC Womens Health. 2010;10:25.

70. O'Leary SA, Link JM, Klineberg EO, Hu JC, Athanasiou KA. Characterization of facet joint cartilage properties in the human and interspecies comparisons. Acta Biomater. 2017:54:367-76.

71. Homminga J, Aquarius R, Bulsink VE, Jansen CT, Verdonschot N. Can vertebral density changes be explained by intervertebral disc degeneration? Med Eng Phys. 2012;34(4):453-8.

72. Bellido M, Lugo L, Roman-Blas JA, Castañeda S, Caeiro JR, Dapia S, Calvo E, Largo R, Herrero-Beaumont G. Subchondral bone microstructural damage by increased remodelling aggravates experimental osteoarthritis preceded by osteoporosis. Arthritis Res Ther. 2010;12(4):R152.

73. Barth M, Weiss C, Thomé C: Two-year outcome after lumbar microdiscectomy versus microscopic sequestrectomy: part 1: evaluation of clinical outcome. Spine (Phila Pa 1976) 2008, 33(3):265-272.

74. Thomé C, Barth M, Scharf J, Schmiedek P. Outcome after lumbar sequestrectomy compared with microdiscectomy: a prospective randomized study. J Neurosurg Spine. 2005;2(3):271-8.

75. Adams MA, Freeman BJ, Morrison HP, Nelson IW, Dolan P: Mechanical initiation of intervertebral disc degeneration. Spine (Phila Pa 1976) 2000, 25(13):1625-1636.

76. Brayda-Bruno M, Albano D, Cannella G, Galbusera F, Zerbi A. Endplate lesions in the lumbar spine: a novel MRI-based classification scheme and epidemiology in low back pain patients. Eur Spine J. 2018;27(11):2854-61.

77. Fakouri B, Patel V, Bayley E, Srinivas S. Lumbar microdiscectomy versus sequesterectomy/free fragmentectomy: a long-term (>2 y) retrospective study of the clinical outcome. J Spinal Disord Tech. 2011;24(1):6-10.

78. Dolan P, Luo J, Pollintine P, Landham PR, Stefanakis M, Adams MA: Intervertebral disc decompression following endplate damage: implications for disc degeneration depend on spinal level and age. Spine (Phila Pa 1976) 2013, 38(17):1473-1481.

79. Wang Y, Videman T, Battié MC: ISSLS prize winner: Lumbar vertebral endplate lesions: associations with disc degeneration and back pain history. Spine (Phila Pa 1976) 2012, 37(17):1490-1496.
80. Tomaszewski KA, Saganiak K, Gładysz T, Walocha JA. The biology behind the human intervertebral disc and its endplates. Folia Morphol (Warsz). 2015;74(2):157-68

81. Roberts S, Evans H, Trivedi J, Menage J. Histology and pathology of the human intervertebral disc. J Bone Joint Surg Am. 2006;88(Suppl 2):10-4.

82. Von Forell GA, Nelson TG, Samartzis D, Bowden AE: Changes in vertebral strain energy correlate with increased presence of Schmorl's nodes in multi-level lumbar disk degeneration. J Biomech Eng 2014, 136(6):061002.

83. Rajasekaran S, Babu JN, Arun R, Armstrong BR, Shetty AP, Murugan S: ISSLS prize winner: A study of diffusion in human lumbar discs: a serial magnetic resonance imaging study documenting the influence of the endplate on diffusion in normal and degenerate discs. Spine (Phila Pa 1976) 2004, 29(23):2654-2667.

84. Xiao L, Ni C, Shi J, Wang Z, Wang S, Zhang J, Lu A. Analysis of Correlation Between Vertebral Endplate Change and Lumbar Disc Degeneration. Med Sci Monit. 2017;23:4932-8.

85. Park P, Garton HJ, Gala VC, Hoff JT, McGillicuddy JE: Adjacent segment disease after lumbar or lumbosacral fusion: review of the literature. Spine (Phila Pa 1976) 2004, 29(17):1938-1944.

86. Patriota GC: Re: two-year outcome after lumbar microdiscectomy versus microscopic sequestrectomy: part 2: radiographic evaluation and correlation with clinical outcome. Spine (Phila Pa 1976) 2008, 33(22):2481; author reply 2481.

87. Grosland NM, Goel VK: Vertebral endplate morphology follows bone remodeling principles. Spine (Phila Pa 1976) 2007, 32(23):E667-673.

88. Wu H, Peng J, Jin X. Internal Biomechanical Study of a 70-Year-Old Female Human Lumbar Bi-Segment Finite Element Model and Comparison with a Middle-Aged Male Model. Biomed Res Int. 2019;2019:9794365.

89. Eubanks JD, Lee MJ, Cassinelli E, Ahn NU: Prevalence of lumbar facet arthrosis and its relationship to age, sex, and race: an anatomic study of cadaveric specimens. Spine (Phila Pa 1976) 2007, 32(19):2058-2062.

90. Vergroesen PP, Kingma I, Emanuel KS, Hoogendoorn RJ, Welting TJ, van Royen BJ, van Dieën JH, Smit TH. Mechanics and biology in intervertebral disc degeneration: a vicious circle. Osteoarthritis Cartilage. 2015;23(7):1057-70.

91. Fan W, Guo LX. Finite element investigation of the effect of nucleus removal on vibration characteristics of the lumbar spine under a compressive follower preload. J Mech Behav Biomed Mater. 2018;78:342-51.

92. Meakin JR, Hukins DW. Effect of removing the nucleus pulposus on the deformation of the annulus fibrosus during compression of the intervertebral disc. J Biomech. 2000;33(5):575-80.

93. Dunlop RB, Adams MA, Hutton WC. Disc space narrowing and the lumbar facet joints. J Bone Joint Surg Br. 1984;66(5):706-10.

94. Bashkuev M, Reitmaier S, Schmidt H. Effect of disc degeneration on the mechanical behavior of the human lumbar spine: a probabilistic finite element study. Spine J. 2018;18(10):1910-20.

\section{Publisher's note}

Springer Nature remains neutral with regard to jurisdictional claims in published maps and institutional affiliations.

Ready to submit your research? Choose BMC and benefit from:

- fast, convenient online submission

- thorough peer review by experienced researchers in your field

- rapid publication on acceptance

- support for research data, including large and complex data types

- gold Open Access which fosters wider collaboration and increased citations

- maximum visibility for your research: over $100 \mathrm{M}$ website views per year

At BMC, research is always in progress.

Learn more biomedcentral.com/submissions 